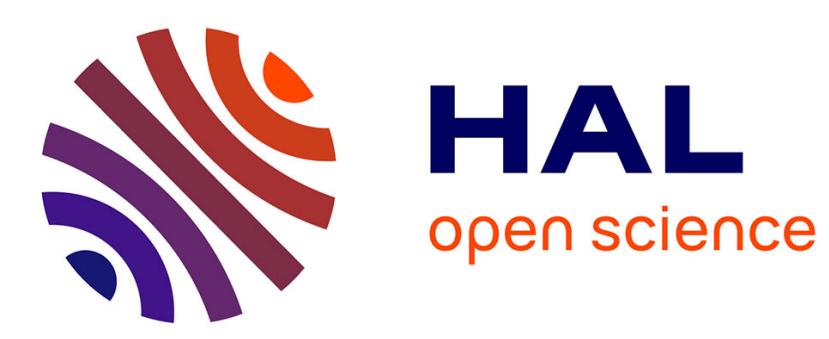

\title{
Antibacterial properties of compounds isolated from
}

\author{
A. Martins, A. Vasas, M. Viveiros, J. Molnár, J. Hohmann, L. Amaral
}

\section{To cite this version:}

A. Martins, A. Vasas, M. Viveiros, J. Molnár, J. Hohmann, et al.. Antibacterial properties of compounds isolated from. International Journal of Antimicrobial Agents, 2011, 37 (5), pp.438. 10.1016/j.ijantimicag.2011.01.016 . hal-00685787

\section{HAL Id: hal-00685787 https://hal.science/hal-00685787}

Submitted on 6 Apr 2012

HAL is a multi-disciplinary open access archive for the deposit and dissemination of scientific research documents, whether they are published or not. The documents may come from teaching and research institutions in France or abroad, or from public or private research centers.
L'archive ouverte pluridisciplinaire HAL, est destinée au dépôt et à la diffusion de documents scientifiques de niveau recherche, publiés ou non, émanant des établissements d'enseignement et de recherche français ou étrangers, des laboratoires publics ou privés. 


\section{Accepted Manuscript}

Title: Antibacterial properties of compounds isolated from Carpobrotus edulis

Authors: A. Martins, A. Vasas, M. Viveiros, J. Molnár, J. Hohmann, L. Amaral

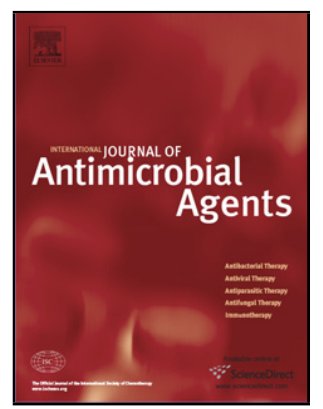

PII: S0924-8579(11)00070-7

DOI: doi:10.1016/j.jjantimicag.2011.01.016

Reference: ANTAGE 3549

To appear in:

International Journal of Antimicrobial

Agents

Received date:

3-1-2011

Revised date:

$17-1-2011$

Accepted date:

$18-1-2011$

Please cite this article as: Martins A, Vasas A, Viveiros M, Molnár J, Hohmann J, Amaral L, Antibacterial properties of compounds isolated from Carpobrotus edulis, International Journal of Antimicrobial Agents (2010), doi:10.1016/j.ijantimicag.2011.01.016

This is a PDF file of an unedited manuscript that has been accepted for publication. As a service to our customers we are providing this early version of the manuscript. The manuscript will undergo copyediting, typesetting, and review of the resulting proof before it is published in its final form. Please note that during the production process errors may be discovered which could affect the content, and all legal disclaimers that apply to the journal pertain. 


\section{Antibacterial properties of compounds isolated from Carpobrotus edulis}

A. Martins ${ }^{a, b, c}$, A. Vasas ${ }^{c}$, M. Viveiros ${ }^{a, d}$, J. Molnár ${ }^{\text {d,e }}$, J. Hohmann ${ }^{c}$, L. Amaral ${ }^{a, b, d, \star}$

a Unit of Mycobacteriology, Instituto de Higiene e Medicina Tropical, Universidade Nova de Lisboa (IHMT/UNL), Rua da Junqueira 96, 1349-008 Lisbon, Portugal

${ }^{\mathrm{b}}$ UPMM, Instituto de Higiene e Medicina Tropical, Universidade Nova de Lisboa (IHMT/UNL), Rua da Junqueira 96, 1349-008 Lisbon, Portugal

${ }^{c}$ Institute of Pharmacognosy, Faculty of Pharmacy, University of Szeged, H-6720

Szeged, Eötvös u. 6, Hungary

${ }^{\mathrm{d}}$ BM0701 Cost Action (ATENS) of the European Commission/European Science Foundation

e Department of Medical Microbiology and Immunobiology, Faculty of Medicine, University of Szeged, H-6720 Szeged, Dóm tér 10, Hungary

ARTICLE INFO

Article history:

Received 3 January 2011

Accepted 18 January 2011

Keywords:

Carpobrotus edulis

Aizoaceae

Isolated compounds 
Staphylococcus aureus

Enterococcus faecalis

Escherichia coli

Salmonella enterica serotype Enteritidis

Mycobacterium tuberculosis

Efflux pumps

Efflux pump inhibition

Multidrug resistance

* Corresponding author. Tel.: +351 21365 2653; fax: +351 213632105 .

E-mail address: lamaral@ihmt.unl.pt (L. Amaral). 


\section{ABSTRACT}

Several compounds isolated from the plant Carpobrotus edulis were evaluated for their activity against multidrug-resistant (MDR) bacteria and their efflux pump systems. Among the compounds isolated, six compounds were tested, namely uvaol, $\beta$-amyrin, oleanolic acid, catechin, epicatechin and monogalactosyldiacylglycerol.

Oleanolic acid presented high antibacterial activity against a large number of bacterial strains. The triterpene uvaol was the most active compound for modulation of efflux activity by MDR Gram-positive strains. 


\section{Introduction}

The plant Carpobrotus edulis is used in sub-Saharan Africa as traditional medicine for symptoms of tuberculosis (TB), throat infections, dysentery, diarrhoea, stomach ailments, burns, chilblains, mouth ulcers, throat infections, sinusitis, toothache, oral and vaginal thrust, etc. [1-5]. This succulent plant is very common in Portugal [6], the Mediterranean countries [5,7], California, USA [8] and South Africa [5].

Extracts of $C$. edulis were previously tested for in vitro and ex vivo activity against Mycobacterium tuberculosis [6,9]. Whereas the methanolic extract of $C$. edulis increased the killing activity of non-killing macrophages infected with Staphylococcus aureus [6], meticillin-resistant $S$. aureus (MRSA) [9] and $M$. tuberculosis [9], it had no activity against these organisms in vitro [9]. This same extract was also shown to reverse the resistance of mouse lymphoma cells that carry the human $m d r 1$ gene to chemotherapeutic agents [6], supposedly by inhibiting P-glycoprotein 1 (P-gp1) of the ABCC1 efflux pump of cancer cells [10]. In our previous study, the compounds uvaol, $\beta$-amyrin, oleanolic acid, catechin, epicatechin and monogalactosyldiacylglycerol (MGDG) isolated from $C$. edulis were evaluated for their anticancer activity and their ability to modulate efflux by the efflux pump ABCC1 [10]. Among these compounds, uvaol was demonstrated to have the greatest capacity to modulate efflux of the efflux pump substrates rhodamine 123 and ethidium bromide (EtBr) by cancer cells as well as acting synergistically with doxorubicin, the anticancer agent to which the cancer cells were initially resistant [10].

Phenolic compounds such as catechin, epicatechin and their derivatives, mainly found in green tea, have been shown to act as antioxidants and to provide protection 
from congestive heart failure [11], to exhibit anti-atherosclerotic [12] and antiinflammatory properties [13] and to inhibit the secretion and production of gastric $\mathrm{H}^{+}$, $\mathrm{K}^{+}$and ATPases [14] and have therefore been considered to act as chemopreventives [15]. Simple phenolic compounds such as epicatechin have also been shown to have antimicrobial properties via a mechanism that disrupts the cell envelope [16]. Catechin has also been identified as an antimicrobial agent with minimum inhibitory concentrations (MICs) between $2 \mathrm{mg} / \mathrm{L}$ and $78 \mathrm{mg} / \mathrm{L}$ against a wide range of Gram-negative bacteria and between $10 \mathrm{mg} / \mathrm{L}$ and $20 \mathrm{mg} / \mathrm{L}$ against Gram-positive bacteria [17]. Catechin has been described to potentiate the action of streptomycin against $M$. tuberculosis infection in mice and to decrease the incidence of pulmonary TB four-fold; this effect has been attributed to their inhibitory effects on fatty acid and mycolic acid biosynthesis [18]. These are important observations, since C. edulis juice is used in traditional medicine for symptoms of pulmonary TB infections. Other flavonoids have been shown to potentiate the action of isoniazid, supposedly by inhibition of the organism's efflux pump system [18], and to inhibit efflux by NorA, the main efflux pump of MRSA strains [19].

Triterpenes such as uvaol, oleanolic acid and $\beta$-amyrin have been shown to exhibit antimycobacterial activity against antibiotic-susceptible and -resistant strains of $M$. tuberculosis [20-24]. These compounds and others from oleane and ursane skeleton triterpenes have been shown to have anti-ulcer, anti-inflammatory, anti-allergic, antinociceptive, antitumour and antiviral properties [25,26]. In 1995, Liu [27] suggested the potential of non-toxic oleanolic acid for therapy of liver failure and systemic inflammatory disorders. 
Because plants employed in traditional medicine that alleviate symptoms of infection have been proven to contain compounds with activity against the very organisms that promote symptoms of infection, compounds isolated from $C$. edulis were evaluated for their in vitro activity against common bacterial pathogens and for activity against the efflux pump system of these same pathogens.

\section{Experimental procedures}

\subsection{Isolation procedures}

Isolation of compounds from $C$. edulis employed in this study has been described in detail previously [10]. The following purified compounds were tested for activity against the efflux pump system of Gram-negative and Gram-positive bacterial pathogens: uvaol; $\beta$-amyrin; oleanolic acid; catechin; epicatechin; and MGDG.

\subsection{Bacterial strains}

Strains used in this study were: $S$. aureus ATCC 25923; an MRSA clinical strain; $S$. aureus HPV 107 and MRSA COL strains (generously provided by Prof. Dr H. de Lencastre); MRSA COL adapted to 1600 mg/L oxacillin (named MRSA COLoxA) [28]; Enterococcus faecalis ATCC 29212; Escherichia coli K-12 AG100 strain [argE3 thi-1 rpsL xyl mtl $\Delta$ (gal-uvrB) supE44] (generously provided by Prof. Dr H. Nikaido) [29]; E. coli AG100 strain exposed to increasing concentrations of tetracycline [30] leading to an efflux pump-overexpressing strain (named E. coli AG100 ${ }_{\mathrm{TET}}$ ); Salmonella enterica serotype Enteritidis; S. Enteritidis 5408; S. Enteritidis $104_{\mathrm{CIP}}$ and S. Enteritidis 5408 $8_{\mathrm{CIP}}$ (Salmonella strains provided by Prof. S. Fanning, adapted to $4 \mathrm{mg} / \mathrm{L}$ and 16 mg/L ciprofloxacin, respectively, and shown to have an overexpressed AcrB 
transporter [31]); and M. tuberculosis H37Rv strain that is susceptible to rifampicin, isoniazid, streptomycin and ethambutol.

\subsection{Cultures}

With the exception of any change specified during each protocol, E. coli strains were grown in Luria-Bertani (LB) broth and LB agar purchased in powder form from Merck (Darmstadt, Germany). Salmonella, Enterobacter, Enterococcus and Staphylococcus strains were grown in tryptone soya broth and tryptone soya agar, both purchased from Oxoid Ltd. (Basingstoke, UK) in powder form. Mycobacterium tuberculosis was grown in Middlebrook 7H9 broth media and Middlebrook 7H11 solid media purchased from Difco (Sparks, MD).

\subsection{Determination of minimum inhibitory concentrations}

MIC determination of the compounds used in the different assays was conducted by the broth microdilution method in Muller-Hinton broth (Oxoid Ltd.) according to Clinical and Laboratory Standards Institute (CLSI) recommendations [32]. The MIC, defined as the lowest concentration of compound that completely inhibits growth as evidenced by absence of turbidity in the medium, was determined after $16 \mathrm{~h}$ of incubation at $37^{\circ} \mathrm{C}$. Each compound was tested to a maximum concentration of 200 $\mathrm{mg} / \mathrm{L}$.

Susceptibility of M. tuberculosis H37Rv to the pure compounds was tested with a BACTEC 460TB system (Becton Dickinson Diagnostic Instrument Systems, Sparks, MD) using BACTEC 12B medium supplemented with $0.1 \mathrm{~mL}$ of PANTA ${ }^{\mathrm{TM}}$ (Quilaban, 
Sintra, Portugal). Cultures were maintained at $37^{\circ} \mathrm{C}$ until the first control reached a maximum growth index (GI) of 999 and the second control reach a Gl of 30 [33]. An aliquot of each vial was plated on $7 \mathrm{H} 11$ agar medium and the plates were incubated at $37^{\circ} \mathrm{C}$ for up to 4 weeks and were subjected to colony-forming unit counts. Details of the above procedures have been described previously $[33,34]$.

2.5. Evaluation of the effects of compounds isolated from Carpobrotus edulis on the minimum inhibitory concentration of a given antibiotic to which the strain was made resistant

The MIC of each antibiotic to which the bacterium was resistant was first determined. The MIC assay for each antibiotic was then performed in the presence and absence of compounds isolated from $C$. edulis at final concentrations of $0.5 \times$ and $0.25 \times \mathrm{MIC}$, if any, or at $50 \mathrm{mg} / \mathrm{L}$ if there was no detectable MIC at concentrations as high as 200 $\mathrm{mg} / \mathrm{L}$.

\subsection{Evaluation of efflux of ethidium bromide (EtBr) by a semi-automated EtBr} method

The modulating activity of each compound on accumulation and efflux of EtBr was assessed by a semi-automated method using a Rotor-Gene $3000^{\mathrm{TM}}$ thermocycler with real-time analysis software (Corbett Research, Sydney, Australia) [35]. Briefly, bacteria were grown to an optical density at $600 \mathrm{~nm}\left(\mathrm{OD}_{600}\right)$ of 0.6 and were washed twice in phosphate-buffered saline $($ PBS) with centrifugation at $3000 \times g$. Pellets were suspended in PBS to yield a final $\mathrm{OD}_{600}$ of 0.6 and $50 \mu \mathrm{L}$ aliquots of this suspension were distributed into microtubes containing $50 \mu \mathrm{L}$ of PBS $(\mathrm{pH} 7)$ containing $1 \mathrm{mg} / \mathrm{L}$ 
$\mathrm{EtBr}$, with and without a source of metabolic energy $(0.4 \%$ glucose $)$ and a milligram quantity of each compound. The concentration of each compound evaluated for effects on the efflux system of a given bacterium was previously determined to have no in vitro activity against that bacterium. The effect on the efflux of EtBr by any compound was evidenced by an increase in the amount of fluorescence of $\mathrm{EtBr}$ accumulated in the cell above that of the compound-free controls. Details of the $\mathrm{EtBr}$ assay have been previously presented in detail $[35,36]$.

\section{Results}

\subsection{In vitro activity of the isolated compounds against bacteria}

The MIC of each compound against pathogenic bacteria was determined in order to define the antibacterial activity of the isolated compounds. As shown in Table 1, the majority of the bacteria tested were resistant to $>200 \mathrm{mg} / \mathrm{L}$ of each compound. Higher concentrations were not tested because higher concentrations of these compounds would not be expected to have clinical significance, as shown by other studies [37].

The compound oleanolic acid was very active against $E$. faecalis, with an MIC of 6.25 $\mathrm{mg} / \mathrm{L}$, and was moderately active against the $S$. aureus strains, which differed with respect to their antibiotic susceptibility pattern. The reference MRSA strain was more resistant to all of the compounds than MRSA COLOXA and HPV 107 strains. Oleanolic acid had the greatest activity against the reference $M$. tuberculosis H37Rv strain. 


\subsection{Modulation of resistance in bacteria}

One of the approaches to find new therapies against multidrug resistance is to search for compounds that increase the susceptibility of the organism to the antibiotics to which it is resistant. Use of such compounds as adjuvants results in a form of synergism that renders the inactive antibiotic active [38].

The methanolic extract of $C$. edulis was previously shown to have no in vitro antibacterial activity against $S$. aureus or $M$. tuberculosis strains. However, because it enhanced the killing of these bacteria post phagocytosis [6,9], regardless of the presence or absence of in vitro activity, all the compounds were evaluated for their ability to reduce or the reverse resistance of pathogenic bacteria to antibiotics to which they were resistant as well as for their activity on the efflux pump system of these bacteria by the semi-automated EtBr method.

Assays evaluating the modulation of antibiotic resistance by a non-antibiotic are performed as follows. First, the MIC of each antibiotic to which the bacterium is resistant and the compound that is to be assayed for modulation of resistance is determined. Second, the assay is repeated for each antibiotic at concentrations from its MIC to one that is deemed as 'clinical susceptibility' in the absence and presence of a concentration of the non-antibiotic that has no effect on the growth of the bacterium. The concentrations chosen for each compound were $\leq 0.5 \times$ MIC. The results of this modulation assay are presented in Tables $2-5$. A minimum four-fold reduction in the MIC of an antibiotic by a given compound was considered significant. 


\subsubsection{Modulation of antibiotic resistance of Gram-negative strains}

The ability of oleanolic acid, uvaol and epicatechin to decrease resistance of $E$. coli AG100 ${ }_{\text {TET8 }}$ strain to tetracycline is shown in Table 2. These compounds decreased the MIC of tetracycline from $25 \mathrm{mg} / \mathrm{L}$ to $6.25 \mathrm{mg} / \mathrm{L}$. However, their activities were not equal inasmuch as the reduction in MIC by some of these compounds required higher concentrations (e.g. the effective concentration of epicatechin was $100 \mathrm{mg} / \mathrm{L}$ compared with that of oleanolic acid which was $50 \mathrm{mg} / \mathrm{L})$. With respect to oleanolic acid, a concentration of $50 \mathrm{mg} / \mathrm{L}$ apparently had reached a saturation of the target (efflux pump) such that higher concentrations of this compound would not increase its effectiveness.

Evaluation of the isolated compounds for reduction in the MIC of ciprofloxacin against Salmonella strains resistant to ciprofloxacin demonstrated that significant reductions could be achieved only by uvaol, MGDG and epicatechin and only for the strain $S$. Enteritidis $5408_{\mathrm{CIP}}$ (Table 3). It is important to note that $S$. Enteritidis $104_{\mathrm{CIP}}$ strain that has been induced to high-level resistance to ciprofloxacin is not affected by any of the compounds. Because resistance to ciprofloxacin in this strain is the result of an increased AcrB transporter, mutations in gyrase $1 \mathrm{~A}$ and two mutations in the stress gene soxS [31], the inability of the compounds to reduce resistance of $S$. Enteritidis $104_{\mathrm{CIP}}$ to ciprofloxacin suggests that the mutated targets beyond the efflux pump itself, such as gyrase, are not sensitive to the isolated compounds.

\subsubsection{Modulation of antibiotic resistance of Gram-positive strains}

An MRSA clinical strain was used to test the ability of $C$. edulis compounds to reduce the MIC of oxacillin, an antibiotic to which that strain is resistant. Resistance of 
MRSA to $\beta$-lactams is due to the acquisition of $m e c A$, a genetic element that carries the resistance gene for this class of antibiotics [39-41]. The origin of this genetic element remains unknown. The mecA element is known to be lost during exposure to an antibiotic of a different class and hence the organism becomes susceptible to $\beta$ lactams [42]. MRSA COL strain whose resistance to oxacillin had been increased from $400 \mathrm{mg} / \mathrm{L}$ to $1600 \mathrm{mg} / \mathrm{L}$ (i.e. MRSA COLOXA) [28], was challenged with each of the compounds for the purpose of determining whether any of the compounds would be able to reduce resistance of this strain to oxacillin. The results presented in Table 4 demonstrate that only uvaol reduces the MIC of oxacillin. None of the compounds, as noted by Table 5, reduced the MIC of oxacillin against the MRSA clinical strain.

\subsection{Activity on accumulation of ethidium bromide}

\subsubsection{Gram-negative bacteria}

The semi-automated $\mathrm{EtBr}$ method affords real-time detection of $\mathrm{EtBr}$ accumulation inside cells by following the evolution of EtBr fluorescence over a period of time. It can be used to evaluate a compound for modulation of accumulation/efflux of EtBr. The modulating activity of a compound increases accumulation and decreases efflux of $\mathrm{EtBr}$, presumably by having an effect on the activity of an efflux pump system. Because of the multiplicity of efflux pumps in Gram-negative bacteria, one cannot at this time specify any given efflux pump as being the one that is affected. However, the main efflux pump of Gram-negative bacteria such as E. coli and Salmonella is the AcrAB pump $[30,43]$. The semi-automated $\mathrm{EtBr}$ method has been used to screen for activity of purified compounds against the AcrAB efflux pump of $E$. coli strains that have been genetically characterised for the degree of expression of genes that 
regulate and code for the AcrB transporter $[30,35,43]$. The effect of each compound on the accumulation and efflux of $\mathrm{EtBr}$ by $E$. coli strains that have been characterised for their efflux pump activity $[30,35,43]$ was conducted using the semi-automated $\mathrm{EtBr}$ method. If compounds are to serve an eventual clinical role for activity against efflux pumps of Gram-negative bacteria that colonise the colon, such as E. coli, the $\mathrm{pH}$ of the medium should be close to that of the colon where the infecting organism resides, namely a pH close to 7 . As evident from Figs 1 and 2 , the compounds catechin and epicatechin were the most effective compounds for increasing the accumulation of $\mathrm{EtBr}$ in strain E. coli $\mathrm{AG} 100$ and hence were assumed to inhibit the intrinsic efflux pump system of E. coli AG100. However, the effects of epicatechin and catechin on the accumulation of $\mathrm{EtBr}$ are inhibited by the presence of glucose. These two compounds do not affect the accumulation of EtBr by the multidrug-

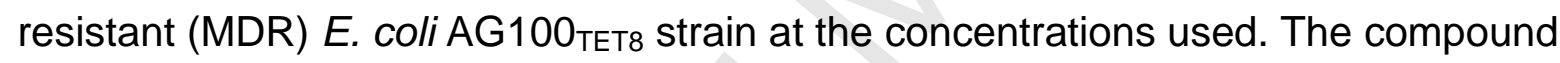
oleanolic acid had a modest effect on the accumulation of EtBr (Fig. 3) and this effect was also inhibited by glucose.

\subsubsection{Gram-positive bacteria}

Because it was observed that some of the compounds reduced the MIC of oxacillin against MRSA COL strain [28], the EtBr accumulation assay was employed to see whether these compounds could affect accumulation/efflux of EtBr by that strain. The MRSA strain used was the MRSA COL adapted to $1600 \mathrm{mg} / \mathrm{L}$ of oxacillin (i.e. MRSA COLOXA) since it was this strain for which the MIC of oxacillin was reduced by some of the isolated compounds. Furthermore, use of the $\mathrm{EtBr}$ assay would also provide an understanding of the physiological conditions that could modulate any noted effect by the compounds on accumulation/efflux of EtBr. As shown by Fig. 4, uvaol increased 
the accumulation of $\mathrm{EtBr}$ by the MRSA COLOXA in a glucose-dependent manner. Similar results were obtained with MGDG (data not shown).

\section{Discussion}

Screening for in vitro activity of the compounds isolated from C. edulis against Gramnegative and Gram-positive bacteria and mycobacteria indicated that none of the compounds were active against Gram-negative bacteria and that some of them were very active against certain Gram-positive bacteria and had moderate activity against M. tuberculosis.

Activities against the MRSA COLOXA and S. aureus HPV 107 strains are of significant clinical importance. In particular, oleanolic acid can be considered to exhibit high activity against the $E$. faecalis strain inasmuch as its MIC of $6.25 \mathrm{mg} / \mathrm{L}$ compares favourably with the susceptibility of this strain to common antibiotics [32]. The activity of oleanolic acid against the M. tuberculosis H37Rv strain is in agreement with the results of others [22].

Previous results showed that the methanolic extract of $C$. edulis could reduce or reverse the resistance of specific bacteria to antibiotics [6]. None of the compounds reduced the resistance of $S$. Enteritidis $104_{\mathrm{CIP}}$ and MRSA to antibiotics to which they were resistant. This suggests that these compounds did not affect the efflux system of these organisms. However, some of the compounds reduced or reversed resistance to some antibiotics in other strains. Among these compounds, uvaol was the compound with the greatest ability to reduce resistance of the MRSA COLOXA strain to oxacillin, the antibiotic to which it was initially resistant. The MRSA COL OXA 
strain owes its MDR phenotype to an overexpressed efflux pump system [28]. The inhibitory effect of uvaol on the accumulation and efflux of EtBr by the MRSA COLoxA strain is glucose-dependent, suggesting that the effect of uvaol on the reduction of oxacillin resistance is due to its effect on the efflux pump system of this organism. Reversal of resistance of other MDR strains to given antibiotics produced by uvaol is also attributed to its effect on their efflux pump system.

Although many compounds have been shown to affect the activity of efflux pumps [44], none have yet been successfully used in a clinical setting as adjuncts with conventional antibiotics for the therapy of MDR bacterial infections. Moreover, most of the compounds that have efflux pump inhibitory activity are also toxic $[45,46]$. Because uvaol is apparently non-toxic [47] at concentrations employed in this study, it promises to be a good candidate as an adjunct to conventional therapy of MDR bacterial infections mediated by an overexpressed efflux pump.

Oleanolic acid, a compound with a similar skeleton to uvaol, was, together with catechin and epicatechin, moderately active in modulating accumulation and efflux of EtBr by E. coli strains. Oleanolic acid is known as an inhibitor of protein kinase, whilst flavonoids have been shown to inhibit the transport of glucose. These two mechanisms prevent the derivation of energy required for efflux pump activity, therefore accumulation takes place. In the presence of glucose, the capacity for inhibition of the efflux pump by oleanolic acid, catechin and epicatechin is lessened, as expected. 
The effects of epicatechin and catechin on the accumulation of EtBr by E. coli AG100 are inhibited by the presence of glucose. This inhibitory effect was repeatable as noted by four different experiments. The reason for this glucose-dependent inhibition of the effects of epicatechin and catechin on the efflux pump system of E. coli AG100 remains unknown although it is under current investigation.

\section{Acknowledgments}

Staphylococcus aureus HPV 107 and MRSA COL were kindly provided by Prof. Hermínia de Lencastre (Molecular Genetics Laboratory, Instituto de Tecnologia Química e Biológica da Universidade Nova de Lisboa, Lisbon, Portugal). Escherichia coli K-12 AG100 strain [argE3 thi-1 rpsL xyl mtl $\Delta$ (gal-uvrB) supE44] was kindly offered by Prof. Dr Hiroshi Nikaido (Department of Molecular and Cell Biology and Chemistry, University of California, Berkeley, CA). Salmonella enterica serotype Enteritidis 104, S. Enteritidis 5408, S. Enteritidis $104_{\mathrm{CIP}}$ and S. Enteritidis $5408_{\mathrm{CIP}}$ were kindly provided by Prof. Seamus Fanning (Centre for Food Safety, School of Agriculture, Food Science and Veterinary Medicine, University College Dublin, Dublin, Ireland).

\section{Funding}

AM was supported by grant SFRH/BD/19445/2004 from the Fundação para a Ciência e a Tecnologia de Portugal (FCT). AV acknowledges the award of a Janos Bolyai Scholarship from the Hungarian Academy of Sciences, Hungarian Research Foundation (OTKA K72771). LA was supported by BCC grant SFRH/BCC/51099/2010 from the FCT. 


\section{Competing interests}

None declared.

\section{Ethical approval}

Not required. 


\section{References}

[1] Mathabe MC, Nikolova RV, Lall N, Nyazema NZ. Antibacterial activities of medicinal plants used for treatment of diarrhoea in Limpopo Province, South Africa. J Ethnopharmacol 2006;105:286-93.

[2] Scott G, Hewett ML. Pioneers in ethnopharmacology: The Dutch East India Company (VOC) at the Cape from 1650 to 1800. J Ethnopharmacol 2008;115:339-60.

[3] Springfield EP, Amabeoku G, Weitz F, Mabusela W, Johnson Q. An assessment of two Carpobrotus species extracts as potential antimicrobial agents. Phytomedicine 2003;10:434-9.

[4] Thring TSA, Weitz FM. Medicinal plant use in the Bredasdorp/Elim region of the Southern Overberg in the Western Cape Province of South Africa. J Ethnopharmacol 2006;103:261-75.

[5] Watt E, Pretorius JC. Purification and identification of active antibacterial components in Carpobrotus edulis. J Ethnopharmacol 2001;76:87-91.

[6] Ordway D, Hohmann J, Viveiros M, Viveiros A, Molnar J, Leandro C, et al. Carpobrotus edulis methanol extract inhibits the MDR efflux pumps, enhances killing of phagocytosed S. aureus and promotes immune modulation. Phytother Res 2003;15:512-9.

[7] Suehs CM, Affre L, Médail F. Invasion dynamics of two alien Carpobrotus (Aizoaceae) taxa on a Mediterranean island: I. Genetic diversity and introgression. Heredity 2004;92:31-40.

[8] Underwood EC, Ustin SL, Ramirez CM. A comparison of spatial and spectral image resolutions for mapping invasive plants in coastal California. Environ Manage 2007;39:63-83. 
[9] Martins M, Ordway D, Kristiansen M, Viveiros M, Leandro C, Molnar J, et al. Inhibition of the Carpobrotus edulis methanol extract on the growth of phagocytosed multidrug-resistant Mycobacterium tuberculosis and methicillinresistant Staphylococcus aureus. Fitoterapia 2005;76:96-9.

[10] Martins A, Vasas A, Schelz Z, Viveiros M, Molnár J, Hohmann J, et al. Constituents of Carpobrotus edulis inhibit P-glycoprotein of mdr1-transfected mouse lymphoma cells. Anticancer Res 2010;30:829-35.

[11] Korish AA, Arafah MM. Catechin combined with vitamins $\mathrm{C}$ and $\mathrm{E}$ ameliorates insulin resistance $(\mathrm{IR})$ and atherosclerotic changes in aged rats with chronic renal failure (CRF). Arch Gerontol Geriatr 2008;46:25-39.

[12] Kawai Y, Tanaka H, Murota K, Naito M, Terao J. (-)-Epicatechin gallate accumulates in foamy macrophages in human atherosclerotic aorta: implication in the anti-atherosclerotic actions of tea catechins. Biochem Biophys Res Comm 2008;374:527-32.

[13] Howells LM, Moiseeva EP, Neal CP, Foreman BE, Andreadi CK, Sun YY, et al. Predicting the physiological relevance of in vitro cancer preventive activities of phytochemicals. Acta Pharmacol Sin 2007;28:1274-304.

[14] Zessner H, Pan L, Will F, Klimo K, Knauft J, Niewöhner R, et al. Fractionation of polyphenol-enriched apple juice extracts to identify constituents with cancer chemopreventive potential. Mol Nutr Food Res 2008;52(Suppl 1):S28-44.

[15] Souccar C, Cysneiros RM, Tanae MM, Torres LM, Lima-Landman MT, Lapa AJ. Inhibition of gastric acid secretion by a standardized aqueous extract of Cecropia glaziovii Sneth and underlying mechanism. Phytomedicine $2008 ; 15: 462-9$. 
[16] Cowan MM. Plant products as antimicrobial agents. Clin Microbiol Rev 1999;12:564-82.

[17] Pfyffer GE, Bonato DA, Ebrahimzadeh A, Gross W, Hotaling J, Kornblum J, et al. Multicenter laboratory validation of susceptibility testing of Mycobacterium tuberculosis against classical second-line and newer antimicrobial drugs by using the radiometric BACTEC 460 technique and the proportion method with solid media. J Clin Microbiol 1999;37:3179-86.

[18] Kuete V, Metuno R, Ngameni B, Mbaveng AT, Ngandeu F, Bezabih M, et al. Antimicrobial activity of the methanolic extracts and compounds from Treculia africana and Treculia acuminata (Moraceae). S Afr J Bot 2008;74:111-5.

[19] Lechner D, Gibbons S, Bucar F. Modulation of isoniazid susceptibility by flavonoids in Mycobacterium. Phytochem Lett 2008;1:71-5.

[20] Stavri M, Piddock LJV, Gibbons S. Bacterial efflux pump inhibitors from natural sources. J Antimicrob Chemother 2007;59:1247-60.

[21] Copp BR, Pearce AN. Natural product growth inhibitors of Mycobacterium tuberculosis. Nat Prod Rep 2007;24:278-97.

[22] Gu JQ, Wang Y, Franzblau SG, Montenegro G, Yang D, Timmermann BN. Antitubercular constituents of Valeriana laxiflora. Planta Med 2004;70:509-14.

[23] Jimenez-Arellanes A, Meckes M, Torres J, Luna-Herrera J. Antimycobacterial triterpenoids from Lantana hispida (Verbenaceae). J Ethnopharmacol 2007;111:202-5.

[24] Woldemichael GM, Franzblau SG, Zhang F, Wang Y, Timmermann BN. Inhibitory effect of sterols from Ruprechtia triflora and diterpenes from Calceolaria pinnifolia on the growth of Mycobacterium tuberculosis. Planta Med 2003;69:62831. 
[25] Woldemichael GM, Wächter G, Singh MP, Maiese WM, Timmermann BN. Antibacterial diterpenes from Calceolaria pinifolia. J Nat Prod 2003;66:242-6.

[26] Farina C, Pinza M, Pifferi G. Synthesis and anti-ulcer activity of new derivatives of glycyrrhetic, oleanolic and ursolic acids. Farmaco 1998;53:22-32.

[27] Liu J. Pharmacology of oleanolic acid and ursolic acid. J Ethnopharmacol 1995;49:57-68.

[28] Martins A, Couto I, Aagaard L, Martins M, Viveiros M, Kristiansen JE, et al. Prolonged exposure of methicillin-resistant Staphylococcus aureus (MRSA) COL strain to increasing concentrations of oxacillin results in a multidrug-resistant phenotype. Int J Antimicrob Agents 2007;29:302-5.

[29] Okusu H, Ma D, Nikaido H. AcrAB efflux pump plays a major role in the antibiotic resistance phenotype of Escherichia coli multiple-antibiotic-resistance (Mar) mutants. J Bacteriol 1996;178:306-8.

[30] Viveiros M, Jesus A, Brito M, Leandro C, Martins M, Ordway D, et al. Inducement and reversal of tetracycline resistance in Escherichia coli K-12 and expression of proton gradient-dependent multidrug efflux pump genes. Antimicrob Agents Chemother 2005;49:3578-82.

[31] O'Regan E, Quinn T, Pagès JM, McCusker M, Piddock L, Fanning S. Multiple regulatory pathways associated with high-level ciprofloxacin and multidrug resistance in Salmonella enterica serovar Enteritidis: involvement of ramA and other global regulators. Antimicrob Agents Chemother 2009;53:1080-7.

[32] Clinical and Laboratory Standards Institute. Performance standards for antimicrobial susceptibility testing; seventeenth informational supplement. Document M100-S17. Wayne, PA: CLSI; 2007. 
[33] Martins M, Schelz Z, Martins A, Molnar J, Hajös G, Riedl Z, et al. In vitro and ex vivo activity of thioridazine derivatives against Mycobacterium tuberculosis. Int J Antimicrob Agents 2007;29:338-40.

[34] Viveiros M, Amaral L. Enhancement of antibiotic activity against poly-drug resistant Mycobacterium tuberculosis by phenothiazines. Int $\mathrm{J}$ Antimicrob Agents $2001 ; 17: 225-8$.

[35] Viveiros M, Martins A, Paixão L, Rodrigues L, Martins M, Couto I, et al. Demonstration of intrinsic efflux activity of Escherichia coli K-12 AG100 by an automated ethidium bromide method. Int J Antimicrob Agents 2008;31:458-62.

[36] Martins A, Spengler G, Rodrigues L, Viveiros M, Ramos J, Martins M, et al. pH modulation of efflux pump activity of multi-drug resistant Escherichia coli: protection during its passage and eventual colonization of the colon. PLoS One 2009;4:e6656.

[37] Gibbons S. Phytochemicals for bacterial resistance—strengths, weaknesses and opportunities. Planta Medica 2008;74:594-602.

[38] Hemaiswarya S, Kruthiventi AK, Doble M. Synergism between natural products and antibiotics against infectious diseases. Phytomedicine 2008;15:639_ 52.

[39] Hussain Z, Stoakes L, Massey V, Diagre D, Fitzgerald V, El Sayed S, et al. Correlation of oxacillin MIC with mecA gene carriage in coagulase-negative staphylococci. J Clin Microbiol 2000;38:752-4.

[40] Klitgaard JK, Skov MN, Kallipolitis BH, Kolmos HJ. Reversal of methicillin resistance in Staphylococcus aureus by thioridazine. J Antimicrob Chemother $2008 ; 62: 1215-21$. 
[41] Severin A, Tabei K, Tenover F, Chung M, Clarke N, Tomasz A. High level oxacillin and vancomycin resistance and altered cell wall composition in Staphylococcus aureus carrying the staphylococcal mecA and the enterococcal vanA gene complex. J Biol Chem 2004;279:3398-407.

[42] Adhikari RP, Scales GC, Kobayashi K, Smith JMB, Berger-Bächi B, Cook GM. Vancomycin-induced deletion of the methicillin resistance gene mecA in Staphylococcus aureus. J Antimicrob Chemother 2004;54:360-3.

[43] Viveiros M, Dupont M, Rodrigues L, Couto I, Davin-Regli A, Martins M, et al. Antibiotic stress, genetic response and altered permeability of E. coli. PLoS One 2007;2:e365.

[44] Pagès J-M, Amaral L. Mechanisms of drug efflux and strategies to combat them: challenging the efflux pump of Gram-negative bacteria. Biochim Biophys Acta 2009;1794:826-33.

[45] Endicott JA, Ling V. The biochemistry of P-glycoprotein-mediated multidrug resistance. Annu Rev Biochem 1989;58:137-71.

[46] Tsuruo T, lida H, Kitatani Y, Yokota K, Tsukagoshi S, Sakrai Y. Effects of quinidine and related compounds on cytotoxicity and cellular accumulation of vincristine and adriamycin in drug-resistant tumor cells. Cancer Res $1984 ; 44: 4303-7$.

[47] Somova LI, Shode FO, Mipando M. Cardiotonic and antidysrhythmic effects of oleanolic and ursolic acids, methyl maslinate and uvaol. Phytomedicine $2004 ; 11: 121-9$ 
Fig. 1. Effect of catechin on the accumulation of ethidium bromide by Escherichia coli AG100 in the presence and absence of glucose $(0.4 \%)$.

Fig. 2. Effect of epicatechin on the accumulation of ethidium bromide by Escherichia coli AG100 in the presence and absence of glucose (0.4\%).

Fig. 3. Effect of oleanolic acid on the accumulation of ethidium bromide by Escherichia coli AG100 TET8 in the presence and absence of glucose $(0.4 \%)$. Escherichia coli AG100 ${ }_{\mathrm{TET}}$ refers to E. coli AG100 strain exposed to increasing concentrations of tetracycline leading to an efflux pump-overexpressing strain.

Fig. 4. Effect of uvaol on the accumulation of ethidium bromide by meticillin-resistant Staphylococcus aureus (MRSA) COLoxA in the presence and absence of glucose (0.4\%). MRSA COLOXA refers to MRSA COL adapted to $1600 \mathrm{mg} / \mathrm{L}$ oxacillin. 


\section{Table 1}

Minimum inhibitory concentrations (MICs) of purified compounds from Carpobrotus edulis on Gram-negative and Gram-positive bacteria and mycobacterial strains

\begin{tabular}{|c|c|c|c|c|c|c|}
\hline \multirow[t]{2}{*}{ Strain $^{a}$} & \multicolumn{6}{|c|}{$\operatorname{MIC}(\mathrm{mg} / \mathrm{L})^{b}$} \\
\hline & $\begin{array}{l}\beta- \\
\text { Amyrin }\end{array}$ & $\begin{array}{l}\text { Oleanolic } \\
\text { acid }\end{array}$ & Uvaol & MGDG & Catechin & Epicatechin \\
\hline $\begin{array}{l}\text { Escherichia coli } \\
\text { AG100 }\end{array}$ & $>200$ & $>200$ & $>200$ & $>200$ & $>200$ & $>200$ \\
\hline E. coli AG100 TET8 & $>200$ & $>200$ & $>200$ & $>200$ & $>200$ & $>200$ \\
\hline $\begin{array}{l}\text { Salmonella enterica } \\
\text { serotype Enteritidis } \\
104\end{array}$ & $>200$ & $>200$ & $>200$ & $>200$ & $>200$ & $>200$ \\
\hline S. Enteritidis $104_{\mathrm{CIP}}$ & $>200$ & $>200$ & $>200$ & $>200$ & $>200$ & $>200$ \\
\hline S. Enteritidis 5408 & $>200$ & $>200$ & $>200$ & $>200$ & $>200$ & $>200$ \\
\hline S. Enteritidis $5408_{\mathrm{CIP}}$ & $>200$ & $>200$ & $>200$ & $>200$ & $>200$ & $>200$ \\
\hline $\begin{array}{l}\text { Enterococcus } \\
\text { faecalis ATCC } \\
29212\end{array}$ & $>200$ & 6.25 & 200 & $>200$ & $>200$ & $>200$ \\
\hline $\begin{array}{l}\text { Staphylococcus } \\
\text { aureus ATCC } 25923\end{array}$ & $>200$ & $>200$ & $>200$ & $>200$ & $>200$ & $>200$ \\
\hline MRSA clinical strain & $>200$ & $>200$ & $>200$ & $>200$ & $>200$ & $>200$ \\
\hline MRSA COL & $>200$ & 50 & 200 & 200 & $>200$ & 200 \\
\hline MRSA COLOXA & 200 & 25 & 100 & 50 & 100 & 100 \\
\hline S. aureus HPV 107 & $>200$ & 25 & 200 & 50 & $>200$ & 100 \\
\hline $\begin{array}{l}\text { Mycobacterium } \\
\text { tuberculosis H37Rv }\end{array}$ & $>200$ & 100 & $>200$ & $>200$ & 200 & $>200$ \\
\hline
\end{tabular}




\section{Table 2}

Effect of compounds isolated from Carpobrotus edulis on the minimum inhibitory concentrations (MICs) of tetracycline (TET) against Escherichia coli AG100 ${ }_{\text {TET8 }}$ a,b

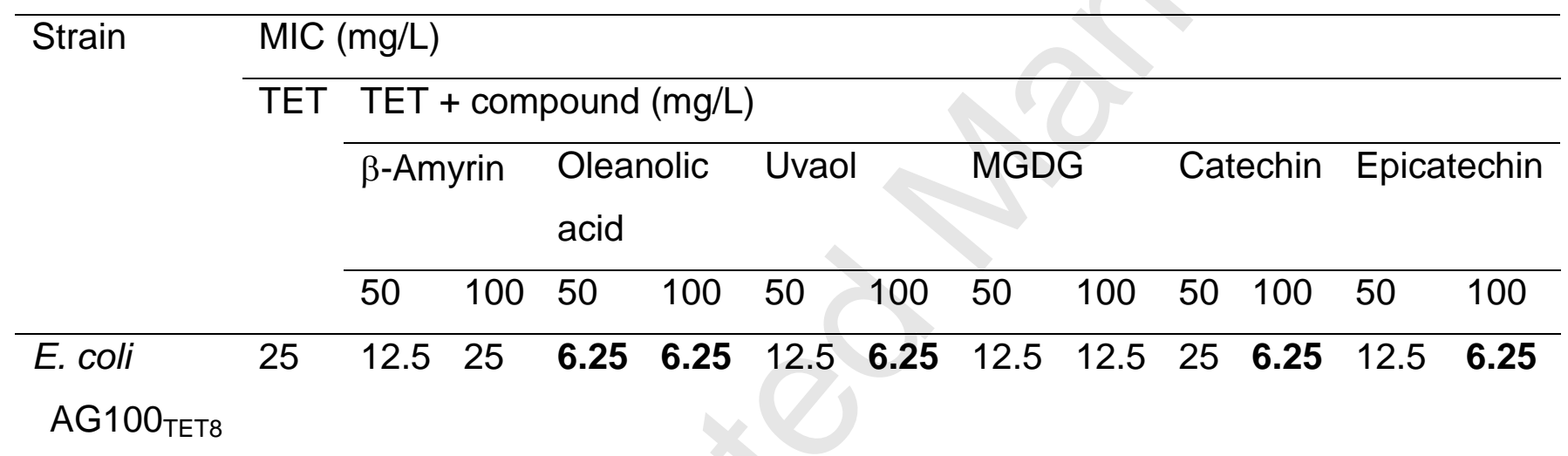

MGDG, monogalactosyldiacylglycerol.

a Escherichia coli AG100 strain exposed to increasing concentrations of tetracycline leading to an efflux pump-overexpressing strain.

${ }^{\mathrm{b}}$ Significant MIC values are highlighted in bold ( $\geq 4$-fold reduction in MIC by a given compound). 


\section{Table 3}

Effect of compounds isolated from Carpobrotus edulis on the minimum inhibitory concentrations (MICs) of ciprofloxacin (CIP) against Salmonella enterica serotype Enteritidis $5408_{\mathrm{CIP}}$ and S. Enteritidis $104_{\mathrm{CIP}}$ a,b

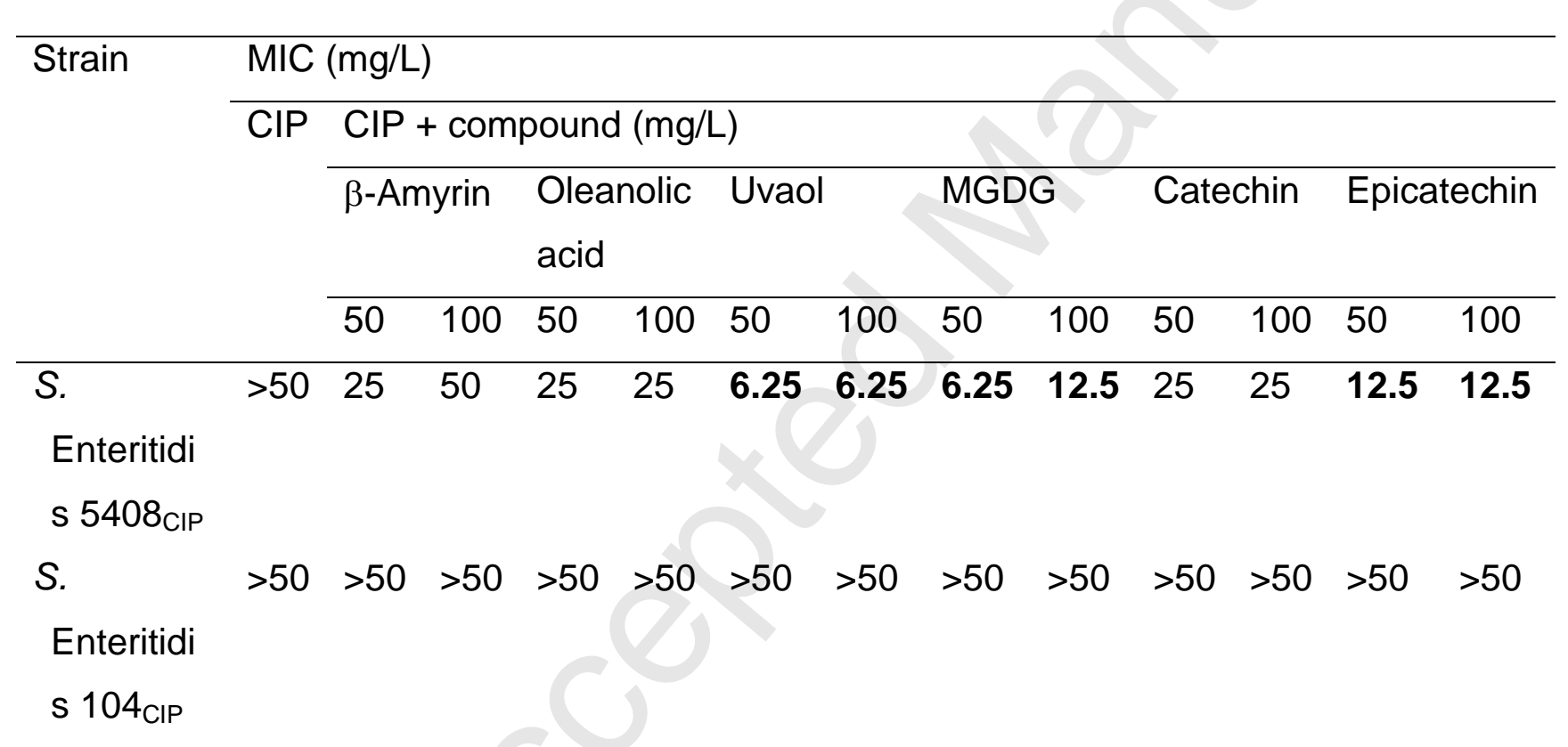

MGDG, monogalactosyldiacylglycerol.

a Salmonella Enteritidis 5408 adapted to $16 \mathrm{mg} / \mathrm{L}$ ciprofloxacin and shown to have an overexpressed AcrB transporter.

${ }^{\mathrm{b}}$ Significant MIC values are highlighted in bold ( $\geq 4$-fold reduction in MIC by a given compound). 


\section{Table 4}

Effect of compounds isolated from Carpobrotus edulis on the minimum inhibitory concentrations (MICs) of oxacillin (OXA) against MRSA COLOXA ${ }^{a, b}$

\begin{tabular}{|c|c|c|c|c|c|c|c|c|c|c|}
\hline \multirow[t]{4}{*}{ Strain } & \multicolumn{10}{|c|}{$\mathrm{MIC}(\mathrm{mg} / \mathrm{L})$} \\
\hline & \multirow[t]{3}{*}{ OXA } & \multicolumn{9}{|c|}{ OXA + compound $(\mathrm{mg} / \mathrm{L})^{c}$} \\
\hline & & \multicolumn{2}{|c|}{$\beta$-Amyrin } & Oleanolic acid & \multirow{2}{*}{$\begin{array}{l}\text { Uvaol } \\
25\end{array}$} & \multicolumn{3}{|c|}{ MGDG } & Catechin & Epicatechin \\
\hline & & 50 & 100 & 10 & & 50 & 12.5 & 25 & 25 & 25 \\
\hline MRSA COL & 1600 & 1600 & 1600 & 1600 & $<100$ & $<100$ & 1600 & 1600 & 16001600 & 16001600 \\
\hline
\end{tabular}

MRSA, meticillin-resistant Staphylococcus aureus; MGDG, monogalactosyldiacylglycerol.

a MRSA COL adapted to $1600 \mathrm{mg} / \mathrm{L}$ oxacillin.

${ }^{\mathrm{b}}$ Significant MIC values are highlighted in bold ( $\geq 4$-fold reduction in MIC by a given compound).

${ }^{c}$ Minimum concentration of OXA used was $100 \mathrm{mg} / \mathrm{L}$ and no growth was observed for uvaol. The results of the assay were read after $48 \mathrm{~h}$ when the strain control also grew. 


\section{Table 5}

Effect of compounds isolated from Carpobrotus edulis on the minimum inhibitory concentrations (MICs) of oxacillin (OXA) against MRSA clinical strain ${ }^{a}$

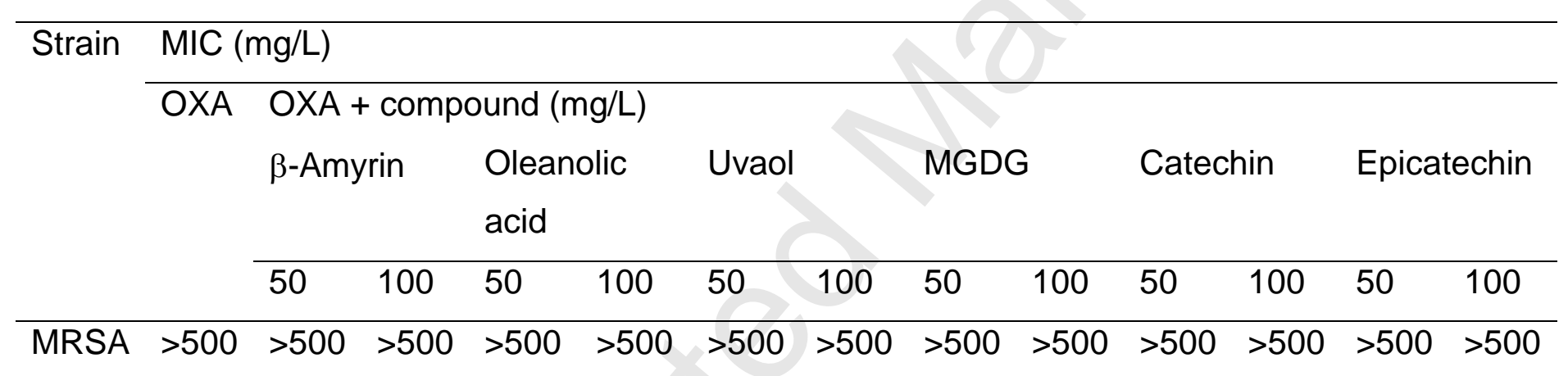

MRSA, meticillin-resistant Staphylococcus aureus; MGDG, monogalactosyldiacylglycerol.

a Significant MIC values are highlighted in bold ( $\geq 4$-fold reduction in MIC by a given compound). 


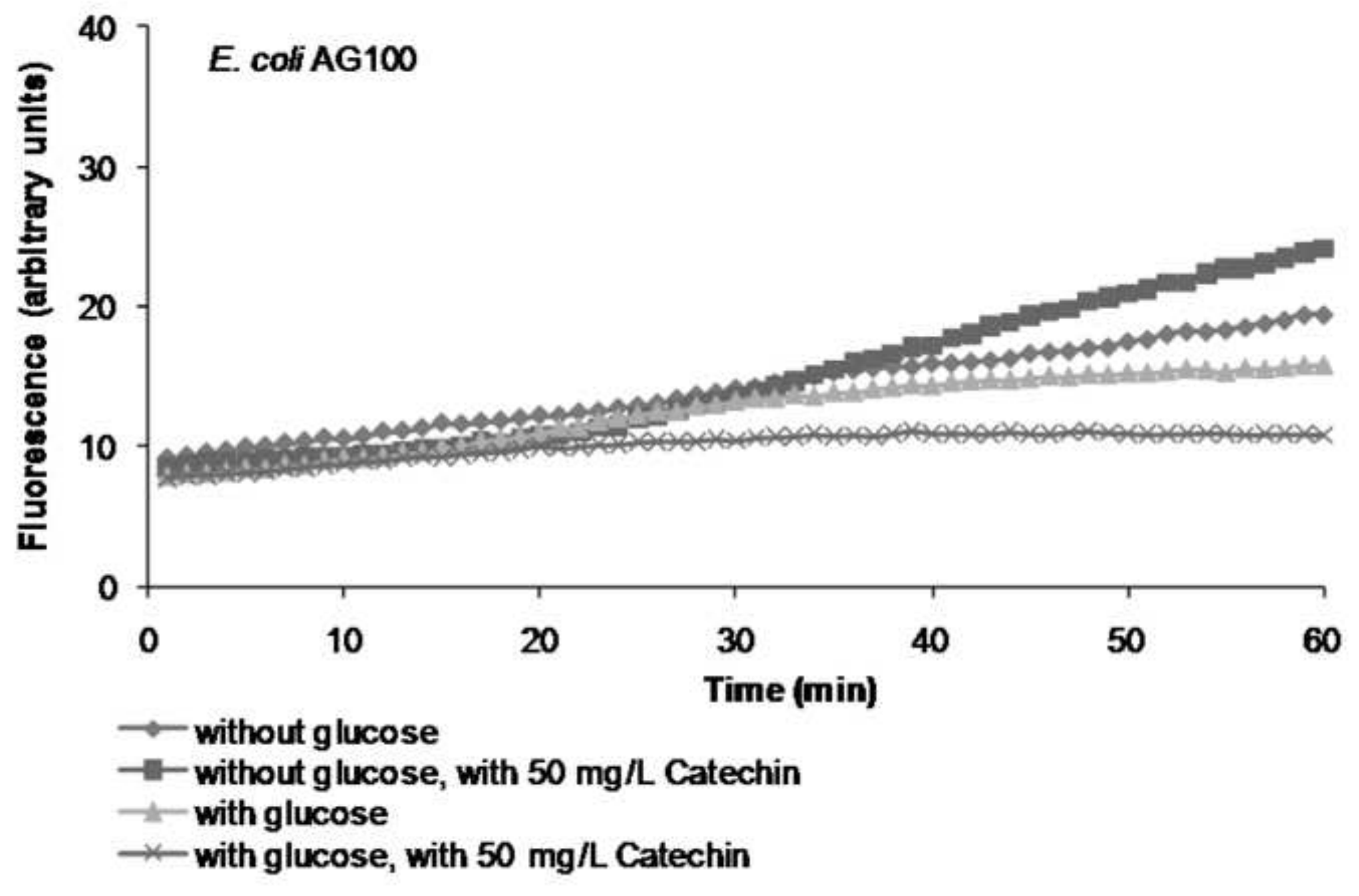

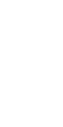

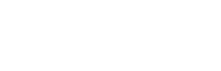




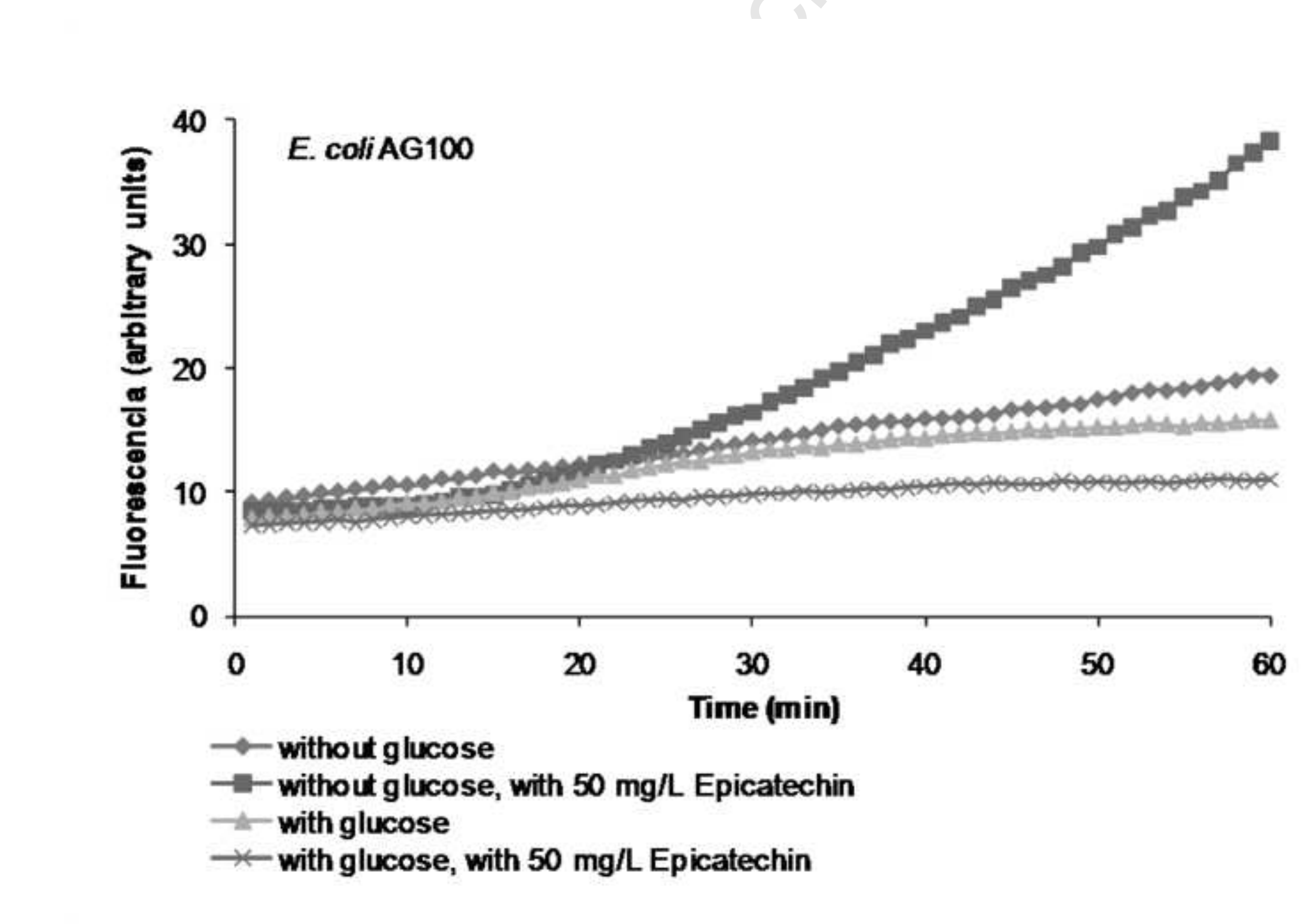

3

\section{Edited Figure 2}

$(2+2$

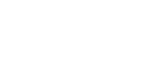




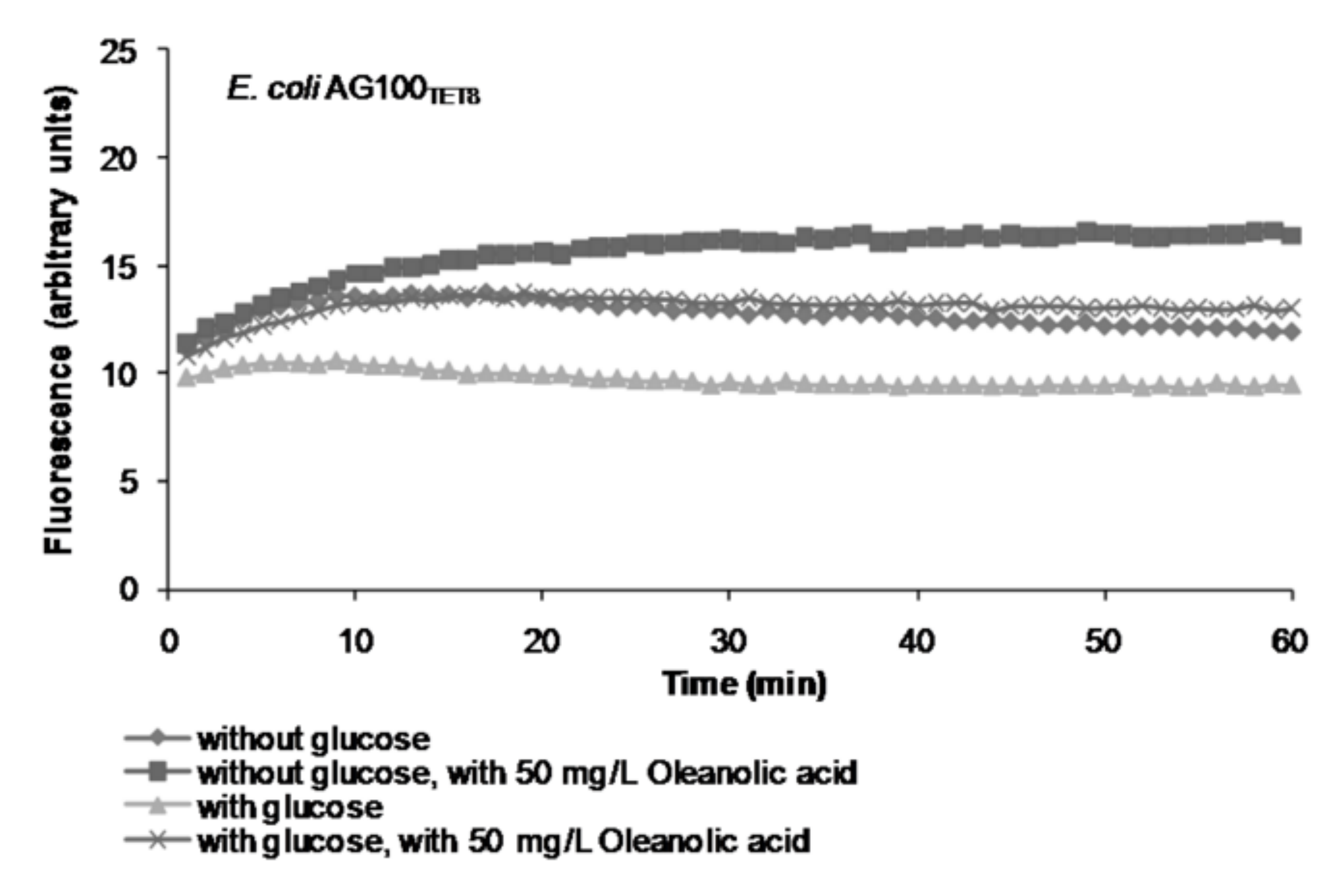

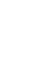

. 


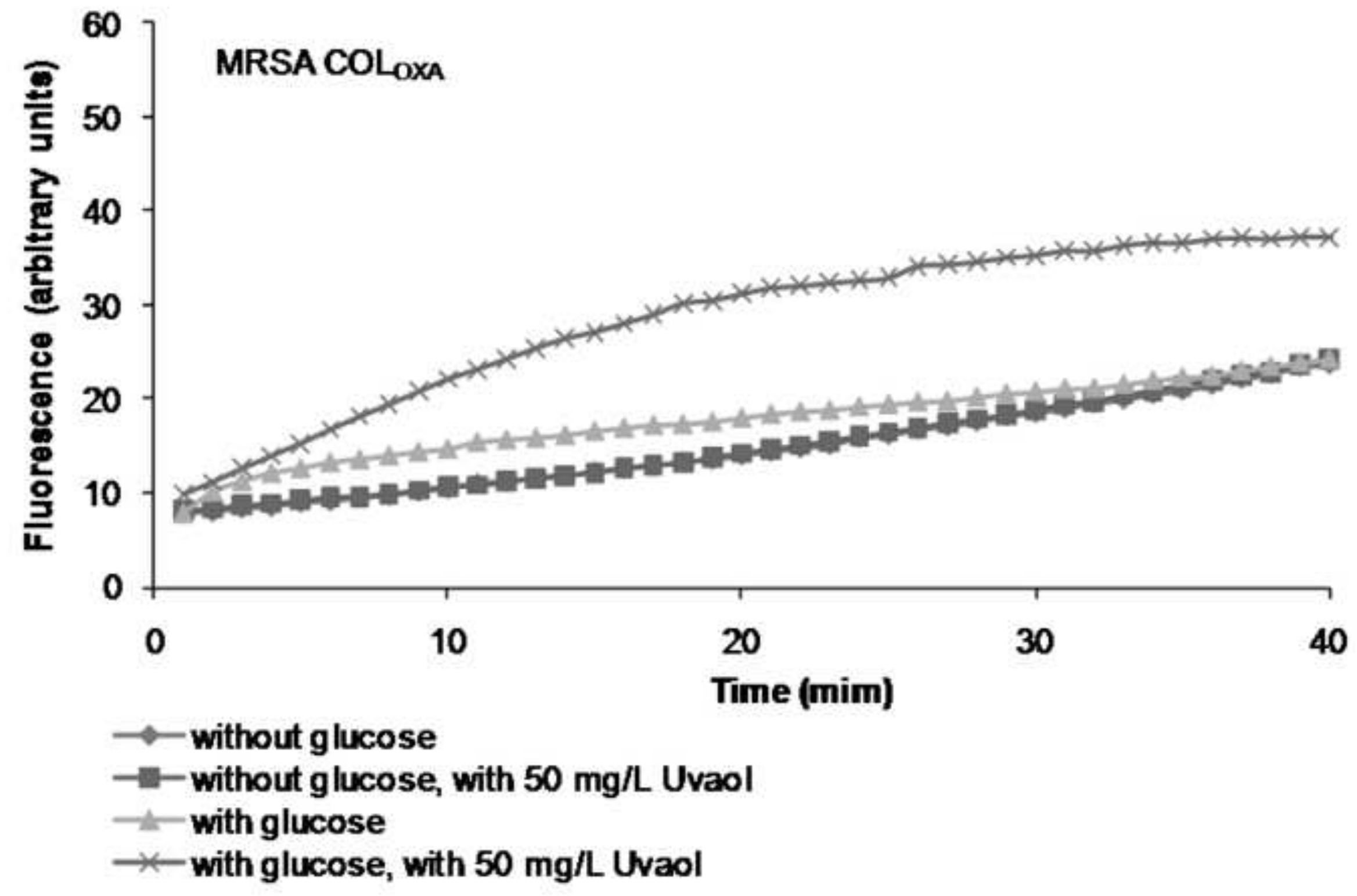

